this country and the Part II in the next 6 months, contingent on their overseas training being recognised by the College. This option may not necessarily be exercised by all trainees but nonetheless needs to be there for those who think themselves ready to sit the examination.

ROYAL COLLEG OF PSYCHIATRISTS (1996) General Information and Regulations for the MRCPsych Examinations. London: RCPsych.

ZUBIN BHAGWAGER, SHO, Old Age Psychiatry, Fulbrook Centre, Churchill Hospital, Old Road, Oxford OX3 7JU

\section{Predicting attendance at child and adolescent peychiatry clinics}

Sir: Not all child psychiatry services have high non-attendance rates and I would suggest that the experience of Potter \& Darwish (Psychiatric Bulletin, December 1996, 20, 717-718) is unusual. Our service has an unnotified non-attendance rate of $13 \%$. This compares favourably with our local paediatric services, and particularly community paediatric services. There is nothing unusual about our services. We are the main child psychiatry provider for a population of about 330000 , have a multidisciplinary clinical staff (excluding trainees) of 11 whole time equivalents and contracts to provide over 5000 appointments per annum. Steadily rising referral rates (more than 1100 new referrals in 1995/6) have caused a waiting list for nonurgent cases of 3 to 6 months.

How have we achieved low non-attendance rates?

Staff attitude: We regard an unnotified nonattendance as a waste of NHS resources and a disservice to other patients. This view is held by all clinical and administrative staff.

First appointments: All patients have to opt in to their first appointment, i.e. they are given an appointment with a date and time and named clinician but asked to confirm attendance within ten days of receiving notification. Fallure to confirm automatically leads to the appointment being vacated and offered to another patient. Our patients appreciate this good management of NHS resources.

Follow-up appointments: All follow-up appointments are booked by the clinician with the family for their mutual convenience. This personal touch probably ensures the patient's realisation that the clinician's time is valuable. Patients who subsequently fail to notify non-attendance at a follow-up appointment are not sent a further appointment, but are sent a letter asking them to contact the clinic to request a further appointment.
Clinician feedback. As part of our internal contract monitoring we provide all clinicians with quarterly feedback on their own clinical activity. This includes numbers of new and follow-up appointments completed, non-attendance rates and individual clinical caseload data. Clinicians are thus aware of their own performance, and of the performance of others.

Purchaser expectations: Our purchasers do not fund patients who do not attend, either by cancellation or by unnotified non-attendance.

Meeting patient expectations: Our contracts specify that referrals have to be made via a GP or paediatrician. This has enabled us to build up a good relationship with a relatively stable group of referers who select and prepare appropriate patients for referral. It is also our impression that patients' cooperation is increased by assessment and treatment procedures which are non-blaming, easy to understand and brief.

K. WEIR, Clinical Director, Child, Adolescent and Family Consultation Service, East Suffolk Local Health Services NHS Trust, 23 Henley Road, Ipswich IPI 3TF

\section{Job-sharing}

Sir: Part-time training including job-sharing is topical in the Psychtatric Bulletin (Abas \& Ramsay, 20, 433; Cremona, 20, 627-624; West $\&$ Taylor, 20, 685-686). Having viewed the jobshare policies of several Trusts in Greater Manchester, a number of pitfalls are evident, especially for training.

It is difficult in a job-share, especially at senior house officer (SHO) level, to fulfil the objective of sharing the responsibilities of a full-time post. Firstly, if each SHO works 2.5 days a week of which one day is a training course, the pair are only on the wards for three days altogether, compared to the four of a full-time employee. In addition, both partners may need to attend ward rounds or case conferences at the same time. further undermining time for clinical work.

Although all policies stated that job-sharers have the same access to training as full-timers, only one stated explicitly that double funding would be avallable for both job-sharers to attend the same course. Attendance at courses needs to be guaranteed for training.

During SHO training, trainees develop different clinical interests and not all will wish to do the same jobs on any rotation. If job-share SHOs are to have the same training opportunities as full timers (a College requirement), they need to have the flexibility to split from their job-share partner to experience different specialities within psychiatry. One policy stated: "Posts filled on a ... fixed term basis will only be agreed for a job 
share where both sharers are available together for the duration of the actual contract period. This applies to . . . junior medical staff". Since breadth of work experience is part of doctors' training, this contradicts other statements on equal training opportunities with full-time staff. There is also no commitment to job security for the remaining partner to complete the rotation if one partner passes MRCPsych and therefore leaves the scheme.

In training for General Practice, six sessions (one session $=0.5$ day) a week are the minimum allowed. The Royal College of Psychiatrists needs to consider whether 10 session job-shares are educationally sound. Trusts need to consider 12 session job-shares in place of 10 session fulltime posts and to review their policies on jobsharing for SHO rotations. Prospective employees need to be aware that local policies may differ and may have pitfalls. Although job-shares may be appropriate for some SHOs, positive action to create individual part-time training posts as an alternative to full-time training is also essential.

Claire Hilton, Senior Registrar, Kendal Day Unit, Bury New Road, Prestwich, Manchester M28 3BL

\section{Section 37 Hospital Order and rights of appeal}

Sir: We note the recent correspondence about Section 37 and rights of appeal (Psychiatric Bulletin. November 1996, 20, 965). C. Clark is correct in stating that patients detained under Section 37 cannot apply to a Mental Health Review Tribunal within the first six months. However, such patients do have another route by which their detention may be reviewed. As a Hospital Order is a form of sentence, patients can appeal against it (Criminal Appeal Act 1968 Section 50 (1)). A defendant may appeal from the Magistrates' Court to the Crown Court. To appeal he must give notice within 21 days after the conviction, to the Magistrates' Clerk and to the prosecution. A defendant may only appeal against sentence passed by the Crown Court either with leave of the Court of Appeal or the Crown Court Judge. The appeal procedure may be seen to be particularly important in the case of individuals placed under a Hospital Order from a Magistrates' Court when no conviction has been recorded, i.e. under the provisions of Section 37(3). Section 45 of the Mental Health Act specifically deals with this issue. It makes the point that any such patients will have the same right of appeal against the order as if it had been made on conviction.

Finally, the responsible medical officer has the discretion to discharge his patient from a hospital order at any time. This could be within the first six months, if appropriate.

These points may address the apparent anomaly between patients detained under Section 3 compared to those held under Section 37.

JONEs R. (1994) Mental Health Act Manual. London: Sweet \& Maxwell.

ELUNED DORKINS and CHRISTINE BROWN, Butler Clinic, Langdon Hospital, Exeter Road, Dawlish, Devon EX7 ONR

\section{Diazepam and detorification}

Sir: Duncan \& Taylor (Psychiatric Bulletin, 1996 , 20, 599-601) discuss chlormethiazole versus chlordiazepoxide in the treatment of the alcohol withdrawal syndrome. The authors do not discuss diazepam, which is safe in home and hospital settings and is avallable as tablet, syrup, rectal and intravenous preparations. Neither chlormethiazole nor chlordiazepoxide allow such flexibility of administration. Diazepam is the treatment of choice for convulsions while parenteral administration of the two drugs recommended is impossible or impracticable.

In the UK, detoxification usually comprises tapering doses of hypnosedatives over a period of 8-14 days. Local research on psychiatric wards suggests that doses prescribed are unrelated to alcohol consumption or past withdrawal symptoms, which risks under- and, more rarely, oversedation. An alternative approach, diazepam "loading dose therapy" has been shown to be effective in the management of moderate to severe alcohol withdrawal syndrome (Sellers et al, 1983) and to be more effective than conventional treatments in the management of delirium tremens (Wasilewski et al, 1996).

Using the traditional method, peak concentrations of long-acting drugs occur not during the first 72 hours, when most desirable, but towards the end of the detoxification period. Loading dose therapy utilises the pharmacokinetic properties of diazepam to minimise the duration of treatment. Diazepam, $20 \mathrm{mg}$ one to two hourly, is titrated against symptoms and signs, measured using the Clinical Institute Withdrawal Assessment scale (CIWA-Ar) (Sullivan et al, 1989). When scores fall below 11, usually within 24 hours, no further drug treatment is required.

This technique appears to be as effective, quicker and safer than standard treatment and is being introduced into the Cardiff service. We would be interested to hear from others who are using this method of treatment. 